\title{
Usefulness of presepsin in predicting the prognosis of patients with sepsis or septic shock: a retrospective cohort study
}

\author{
Jeong Suk Koh, Yoon Joo Kim, Da Hyun Kang, Jeong Eun Lee, Song-I Lee \\ Department of Pulmonary and Critical Care Medicine, Chungnam National University School of Medicine, Daejeon, Korea
}

Received: March 19, 2021

Revised: May 4, 2021

Accepted: May 12, 2021

Corresponding author:

Song-I Lee, MD

Department of Pulmonary and

Critical Care Medicine, Chungnam

National University School of

Medicine, 282 Munhwa-ro, Jung-

gu, Daejeon 35015, Korea

Tel: +82-42-280-6816

Fax: +82-42-257-5753

E-mail: newcomet01@naver.com
Background: The diagnosis and prediction of prognosis are important in patients with sepsis, and presepsin is helpful. In this study, we aimed to examine the usefulness of presepsin in predicting the prognosis of sepsis in Korea.

Methods: Patients diagnosed with sepsis according to the sepsis-3 criteria were recruited into the study and classified into surviving and non-surviving groups based on in-hospital mortality. A total of 153 patients (32 and 121 patients with sepsis and septic shock, respectively) were included from July 2019 to August 2020.

Results: Among the 153 patients with sepsis, 91 and 62 were in the survivor and non-survivor groups, respectively. Presepsin $(p=0.004)$ and lactate $(p=0.003)$ levels and the sequential organ failure assessment (SOFA) score $(p<0.001)$ were higher in the non-survivor group. Receiver operating characteristic curve analysis revealed poor performances of presepsin and lactate in predicting the prognosis of sepsis (presepsin: area under the curve $[A U C]=0.656, p=0.001$; lactate: $\mathrm{AUC}=0.646, p=0.003$ ). The SOFA score showed the best performance, with the highest $A U C$ value (AUC $=0.751, p<0.001$ ). The prognostic cutoff point for presepsin was $1,176 \mathrm{pg} / \mathrm{mL}$. Presepsin levels higher than $1,176 \mathrm{pg} / \mathrm{mL}$ (odds ratio [OR], 3.352; $p<0.001$ ), higher lactate levels $(O R, 1.203 ; p=0.003)$, and higher SOFA score $(O R, 1.249 ; p<0.001)$ were risk factors for in-hospital mortality.

Conclusion: Presepsin levels were higher in non-survivors than in survivors. Thus, presepsin may be a valuable biomarker in predicting the prognosis of sepsis.

Keywords: Biomarkers; Prognosis; Sepsis; Septic shock

\section{Introduction}

Sepsis is a condition that is accompanied by systemic inflammatory reactions caused by infection and major organ failure [1]. If not detected and treated quickly, the mortality rate reaches $40 \%$ to $70 \%[2,3]$. The treatment of sepsis requires the key elements of intensive care unit (ICU) treatment, such as hemodynamic monitoring and support, ventilator therapy, and renal replacement ther- apy [4]. It is well known that the early diagnosis and proper treatment of sepsis can improve prognosis and increase the survival of people with sepsis [5].

In 2001, the sepsis mortality rate in the United States was 28.6\% and has recently declined to $20 \%$ [6]. Moreover, the sepsis mortality rate in Australia and New Zealand has been reported to be $18.4 \%$ [7]. Unfortunately, the sepsis mortality rate in Korea is far higher than that in developed countries. Currently, the mortality

Copyright (C) 2021 Yeungnam University College of Medicine

This is an Open Access article distributed under the terms of the Creative Commons Attribution Non-Commercial License (http://creativecommons.org/licenses/by-nc/4.0/) which permits unrestricted non-commercial use, distribution, and reproduction in any medium, provided the original work is properly cited. 
rate of sepsis in Korea, as reported by the Korean Society of Critical Care Medicine in 2013, is 37.8\%, and the number of deaths from sepsis in the same year was 15,076, which constituted a large percentage of total deaths [2]. Moreover, in Korea, as the number of elderly and immunocompromised patients increases rapidly, the social burden from sepsis is expected to increase significantly in the near future.

Among various molecules, presepsin appears to be a promising biomarker, as it has been reported to be involved in the early stages of the septic process [8]. When monocytes are activated by an infectious agent, the soluble CD14 subtype, presepsin, is released into the plasma [9]. Subsequently, presepsin levels continue to increase in the early stages of sepsis. In Korea, presepsin levels were significantly higher in the infected group than in the uninfected group [10]. In this study, we examined whether presepsin levels are an effective marker for predicting prognosis in patients with sepsis or septic shock.

\section{Materials and methods}

\section{Study population and study design}

All study data were retrieved from electronic medical records (C\&U care, Daejeon, Korea). Patients who were diagnosed with sepsis or septic shock by a physician and those whose presepsin levels were checked were included in the study. Sepsis was defined as life-threatening organ dysfunction caused by a dysregulated host response to infection. Organ dysfunction was identified as an acute change in the total sequential organ failure assessment (SOFA) score of $\geq 2$ points consequent to the infection. Septic shock was defined based on the sepsis-3 criteria as the presence of the following conditions: (1) sepsis, (2) need for vasopressor/ inotropes to maintain mean blood pressure of $\geq 65 \mathrm{mmHg}$, and (3) lactate of $>2 \mathrm{mmol} / \mathrm{L}$, even with sufficient fluids [1]. For this study, we included all adult patients who were admitted to the ICU directly from the emergency department or ward. The inclusion criteria were: more than 18 years of age, diagnosis of sepsis or septic shock, and presepsin levels measured. Exclusion criteria were: not admitted to the ICU, presepsin levels not measured, and incomplete data. A total of 153 patients were included in the period between July 2019 and August 2020 (Fig. 1).

Age, sex, laboratory data (white blood cell [WBC] and platelet counts, total bilirubin, creatinine, procalcitonin, and lactate levels), and blood samples were collected from patients with sepsis or septic shock. The presepsin levels in the blood samples were measured using an automated analyzer (LSI Medience Corp., Tokyo, Japan) with a detection range of 20 to $20,000 \mathrm{pg} / \mathrm{mL}$. Clinical data related to patient prognosis were collected during the hospital stay. The patients
297 Patients with sepsis or septic shock

July 1, 2019-August 31, 2020

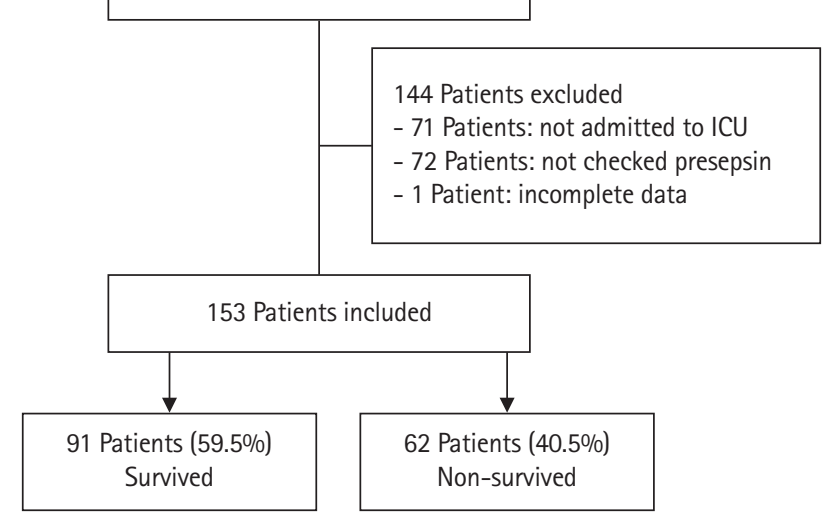

Fig. 1. Flowchart of patients. ICU, intensive care unit.

were observed from the date of admission to the date of discharge or death. Subsequently, a retrospective analysis was performed.

\section{Statistical analysis}

All values are expressed as mean \pm standard deviations for continuous variables and as percentages for categorical variables. Student $t$-test or Mann-Whitney U-test was used for continuous data, and Pearson chi-squared test or Fisher exact test was used for categorical data. Receiver operating characteristic (ROC) curve analysis was performed to evaluate prediction accuracy. The optimal cutoff value was chosen as the highest product of sensitivity and specificity. Univariate logistic regression analysis was performed to identify predictors of in-hospital mortality. All $p$-values were two-tailed, with statistical significance set at $p<0.05$. All the statistical analyses were performed using IBM SPSS version 22.0 (IBM Corp., Armonk, NY, USA).

\section{Results}

\section{Baseline characteristics of patients}

The baseline characteristics of the 153 studied patients are shown in Table 1. The non-survivor group had older patients $(72.2 \pm 12.5$ years vs. $67.0 \pm 14.6$ years, $p=0.025$ ) and higher 30 -day mortality ( $72.6 \%$ vs. $0 \%, p<0.001)$; additionally, the number of patients receiving ventilatory assistance during the ICU stay was higher in the non-survivor group than in the survivor group ( $87.1 \%$ vs. $47.3 \%$, $p<0.001$ ) (Table 1).

The presepsin $(3,112 \pm 3,841 \mathrm{pg} / \mathrm{mL}$ vs. $1,511 \pm 2,092 \mathrm{pg} / \mathrm{mL}$, $p=0.004)$ and lactate $(4.3 \pm 3.3 \mathrm{mmol} / \mathrm{L}$ vs. $2.8 \pm 2.4 \mathrm{mmol} / \mathrm{L}$, $p=0.003)$ levels and the SOFA score $(12 \pm 4$ vs. $8 \pm 4, p<0.001)$ were higher in the non-survivor group than in the survivor group 
Table 1. Patients' baseline characteristics

\begin{tabular}{|c|c|c|c|c|}
\hline Characteristic & Total & Survivor group & Non-survivor group & $p$-value ${ }^{\text {a) }}$ \\
\hline No. of patients & 153 & 91 & 62 & \\
\hline Age (yr) & $69.1 \pm 14.0$ & $67.0 \pm 14.6$ & $72.2 \pm 12.5$ & 0.025 \\
\hline Male sex & $94(61.4)$ & $59(64.8)$ & $35(56.5)$ & 0.296 \\
\hline Body mass index $\left(\mathrm{kg} / \mathrm{m}^{2}\right)$ & $23.7 \pm 12.7$ & $24.3 \pm 16.3$ & $22.9 \pm 4.2$ & 0.515 \\
\hline \multicolumn{5}{|l|}{ Laboratory value } \\
\hline WBC $(/ \mu \mathrm{L})$ & $13,285 \pm 9,164$ & $13,212 \pm 8,642$ & $13,393 \pm 9,953$ & 0.905 \\
\hline Platelets $\left(\times 10^{3} / \mu \mathrm{L}\right)$ & $154 \pm 108$ & $168 \pm 109$ & $133 \pm 103$ & 0.052 \\
\hline Total bilirubin (mg/dL) & $2.0 \pm 3.0$ & $1.6 \pm 2.3$ & $2.7 \pm 3.8$ & 0.044 \\
\hline Creatinine (mg/dL) & $1.6 \pm 1.4$ & $1.6 \pm 1.6$ & $1.8 \pm 1.3$ & 0.415 \\
\hline $\mathrm{CRP}(\mathrm{mg} / \mathrm{dL})$ & $15.5 \pm 10.2$ & $16.1 \pm 10.1$ & $14.7 \pm 10.3$ & 0.414 \\
\hline Procalcitonin (ng/mL) & $18.9 \pm 42.5$ & $16.4 \pm 40.3$ & $22.7 \pm 45.7$ & 0.378 \\
\hline Presepsin (pg/mL) & $2,159 \pm 3,022$ & $1,511 \pm 2,092$ & $3,112 \pm 3,841$ & 0.004 \\
\hline Lactate (mmol/L) & $3.4 \pm 2.9$ & $2.8 \pm 2.4$ & $4.3 \pm 3.3$ & 0.003 \\
\hline \multicolumn{5}{|l|}{ Severity of sepsis } \\
\hline APACHE II score & $19 \pm 10$ & $18 \pm 8$ & $21 \pm 11$ & 0.051 \\
\hline SOFA score & $10 \pm 4$ & $8 \pm 4$ & $12 \pm 4$ & $<0.001$ \\
\hline Sepsis & $32(20.9)$ & $21(23.1)$ & $11(17.7)$ & 0.342 \\
\hline Septic shock & $121(79.1)$ & 70 (76.9) & $51(82.3)$ & 0.426 \\
\hline 30-Day mortality & $45(29.4)$ & $0(0)$ & $45(72.6)$ & $<0.001$ \\
\hline \multicolumn{5}{|l|}{ Treatment during ICU stay } \\
\hline Mechanical ventilation & $97(63.4)$ & $43(47.3)$ & $54(87.1)$ & $<0.001$ \\
\hline Vasopressors & 109 (71.2) & $61(67.0)$ & $48(77.4)$ & 0.163 \\
\hline
\end{tabular}

Values are presented as number only, mean \pm standard deviation, or number $(\%)$.

WBC, white blood cell; CRP, C-reactive protein; APACHE II, Acute Physiology and Chronic Health Evaluation II; SOFA, sequential organ failure assessment; $I C U$, intensive care unit.

${ }^{\text {a) }}$ Analyzed between survivor and non-survivor groups.

(Fig. 1). However, there was no significant difference in the WBC counts $(13,212 \pm 8,642 / \mu \mathrm{L}$ vs. $13,393 \pm 9,953 / \mu \mathrm{L}, p=0.905)$, C-reactive protein (CRP) $(16.1 \pm 10.1 \mathrm{mg} / \mathrm{dL}$ vs. $14.7 \pm 10.3 \mathrm{mg} /$ $\mathrm{dL}, p=0.414)$ levels, procalcitonin levels $(16.4 \pm 40.3 \mathrm{ng} / \mathrm{mL}$ vs. $22.7 \pm 45.7 \mathrm{ng} / \mathrm{mL}, p=0.378)$, and Acute Physiology and Chronic Health Evaluation II (APACHE II) score (18 \pm 8 vs. $21 \pm 11$, $p=0.051$ ) between the two groups (Fig. 2).

\section{Comparison of the infection sources and pathogens between the two groups}

The frequency of urinary tract infection was lower in the non-survivor group $(6.5 \%$ vs. $18.7 \%, p=0.031)$ than in the survivor group. There was no significant difference in the other sources of infection (Table 2).

The frequency of fungal infections was higher $(9.7 \%$ vs. $0 \%$, $p=0.002$ ) in the non-survivor group than in the survivor group, while those of bacterial and viral infections were not significantly different between the two groups (Table 2).

\section{Predictors of patients' in-hospital mortality}

A binary logistic regression analysis showed that a presepsin levels higher than $1,176 \mathrm{pg} / \mathrm{mL}$ (odds ratio [OR], 3.352; 95\% confidence interval [CI], 1.707-6.585; $p<0.001)$, higher lactate levels (OR, 1.203; 95\% CI, 1.063-1.361; $p=0.003$ ), and higher SOFA score (OR, 1.249; 95\% CI, 1.136-1.373; $p<0.001$ ) were risk factors for in-hospital mortality due to sepsis (Table 3 ). However, there was no association between in-hospital mortality and WBC, $\mathrm{CRP}$, and procalcitonin levels. When presepsin was used as a continuous variable, there was no meaningful value with OR of 1.000 (95\% CI, 1.000-1.000; $p=0.047$ ). However, when the cutoff value was applied, a meaningful value was confirmed for presepsin.

\section{Prognostic value of the sepsis biomarker and the SOFA score}

The performances of the levels of WBC, CRP, procalcitonin, presepsin, lactate, and SOFA score in predicting in-hospital mortality from sepsis were evaluated using ROC curves (Fig. 3). The levels of presepsin and lactate demonstrated poor performance in predicting the prognosis of sepsis (presepsin: area under the curve 

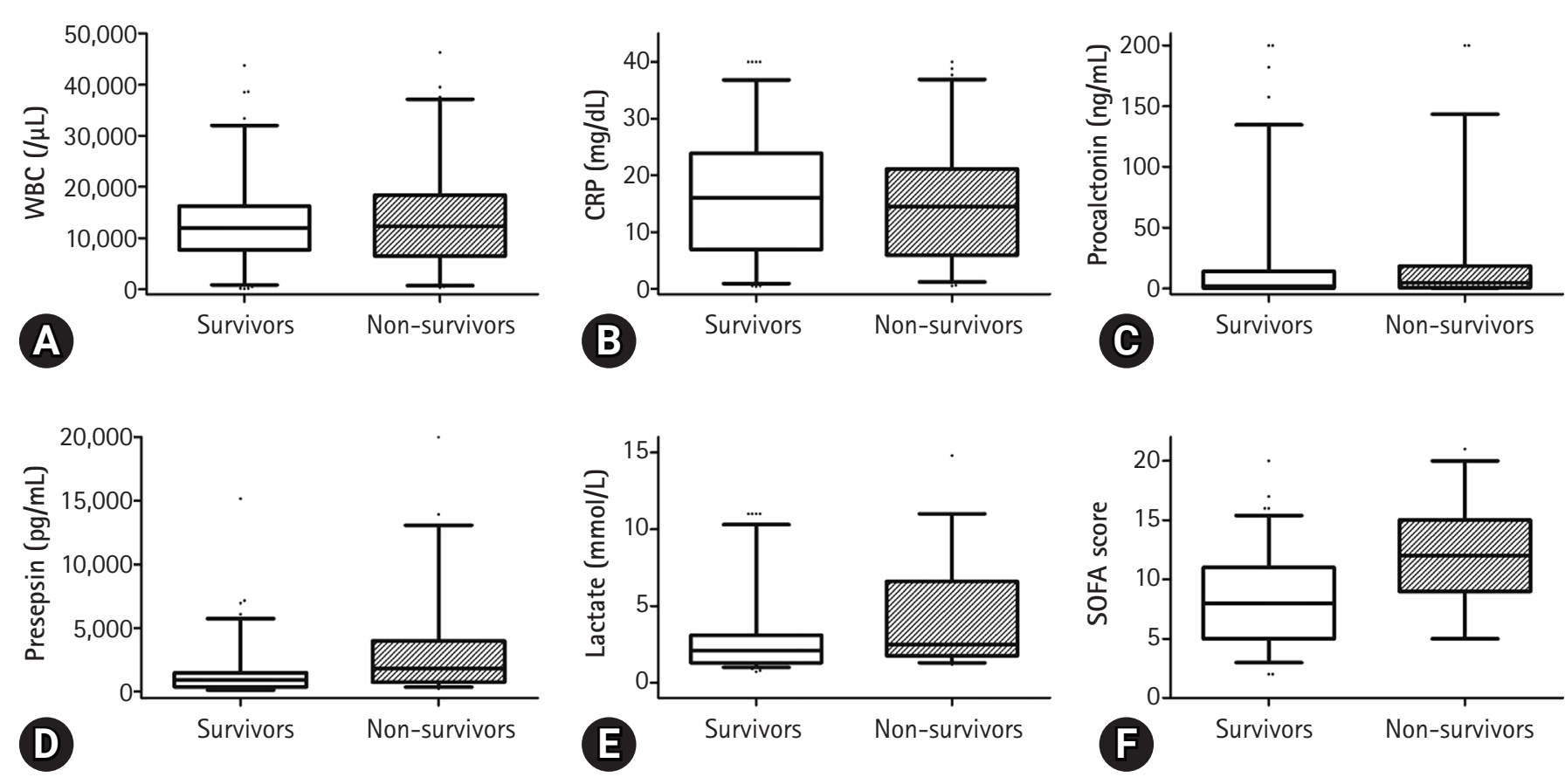

Fig. 2. Vertical box-and-whiskers plots summarizing laboratory data on all bombarded construct combinations. The whiskers indicate the 5th-95th percentile: any data points outside of this are shown as dots. (A) White blood cells (WBC) counts, (B) C-reactive protein (CRP), (C) procalcitonin level, (D) presepsin levels, (E) lactate levels, and (F) the sequential organ failure assessment (SOFA) score in the survivor and non-survivor groups.

Table 2. Infection sources and pathogens of patients

\begin{tabular}{|c|c|c|c|c|}
\hline Variable & Total $(n=153)$ & Survivor group $(n=91)$ & Non-survivor group $(n=62)$ & $p$-value ${ }^{a l}$ \\
\hline \multicolumn{5}{|l|}{ Sources of infection } \\
\hline Respiratory tract & $92(60.1)$ & $54(59.3)$ & $38(61.3)$ & 0.809 \\
\hline Urinary tract & $21(13.7)$ & 17 (18.7) & $4(6.5)$ & 0.031 \\
\hline Intra-abdomen & $19(12.4)$ & $9(9.9)$ & $10(16.1)$ & 0.251 \\
\hline Others ${ }^{b)}$ & $23(15.0)$ & $12(13.2)$ & $11(17.7)$ & 0.439 \\
\hline \multicolumn{5}{|l|}{ Pathogens } \\
\hline Gram (-) rods & $30(19.6)$ & $21(23.1)$ & $9(14.5)$ & 0.190 \\
\hline Gram (-) bacilli & $37(24.2)$ & $15(16.5)$ & $9(14.5)$ & 0.743 \\
\hline Gram (+) cocci & $37(24.2)$ & $24(26.4)$ & $13(21.0)$ & 0.443 \\
\hline Gram (+) bacilli & $5(3.3)$ & $1(1.1)$ & $4(6.5)$ & 0.068 \\
\hline Fungus & $6(3.9)$ & $0(0)$ & $6(9.7)$ & 0.002 \\
\hline Virus & $5(3.3)$ & $5(5.5)$ & $0(0)$ & 0.061 \\
\hline Negative cultures & $47(30.7)$ & $27(29.7)$ & $20(32.3)$ & 0.733 \\
\hline
\end{tabular}

Values are presented as number (\%).

If there are multiple sources of infection and/or pathogens in one patient, all of them are shown in the table.

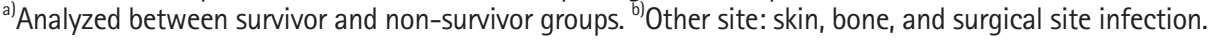

$[\mathrm{AUC}]=0.656, p=0.001$; lactate: $\mathrm{AUC}=0.646, p=0.003)$. The SOFA score had the best performance, with the highest AUC value $(\mathrm{AUC}=0.751, p<0.001)$. The prognostic cutoff value for presepsin was $1,176 \mathrm{pg} / \mathrm{mL}$, at which the sensitivity and specificity were $66.7 \%$ and $61.1 \%$, respectively. In addition, the prognostic cutoff value of the SOFA score was 9.50 (sensitivity, $72.6 \%$; speci- ficity, $67.0 \%)$, and the prognostic cutoff value of lactate was 1.55 (sensitivity, 91.8\%; specificity, 34.8\%). The Pearson correlation coefficient of the SOFA score and presepsin was $0.421(p<0.001)$, which had a moderate quantitative linear relationship. 


\section{Discussion}

The patients were divided into two groups, and a retrospective analysis was performed according to in-hospital mortality. We evaluated the performance of presepsin as a biomarker for predicting in-hospital mortality in patients with sepsis. Presepsin levels were higher in the non-survivor group than in the survivor group. The levels of presepsin displayed poor performance in predicting the prognosis of sepsis (presepsin: $\mathrm{AUC}=0.656, p=0.001$ ), and the prognostic accuracy of presepsin was $1,176 \mathrm{pg} / \mathrm{mL}$, with a sensitivity and specificity of $66.7 \%$ and $61.1 \%$, respectively. Presepsin levels higher than $1,176 \mathrm{pg} / \mathrm{mL}$ were a significant predictor of in-hospital mortality.

Presepsin is a $13-\mathrm{kDa}$ glycoprotein-truncated N-terminal frag-

Table 3. Univariate binary logistic regression analysis results in inhospital mortality

\begin{tabular}{lcc}
\hline Parameter & OR $(95 \% \mathrm{Cl})$ & $p$-value \\
\hline White blood cells & $1.000(1.000-1.000)$ & 0.905 \\
C-reactive protein & $0.987(0.955-1.019)$ & 0.411 \\
Procalcitonin & $1.003(0.996-1.011)$ & 0.380 \\
Presepsin $(>1,176 \mathrm{pg} / \mathrm{mL})$ & $3.352(1.707-6.585)$ & $<0.001$ \\
Lactate & $1.203(1.063-1.361)$ & 0.003 \\
APACHE II score & $1.035(1.000-1.072)$ & 0.053 \\
SOFA score & $1.249(1.136-1.373)$ & $<0.001$
\end{tabular}

$\mathrm{OR}$, odds ratio; $\mathrm{Cl}$, confidence interval; $\mathrm{APACHE}$ II, Acute Physiology and Chronic Health Evaluation II; SOFA, sequential organ failure assessment. ment of CD14 that activates the pro-inflammatory signaling stage after it is released into the circulation following contact with an infectious pathogen $[11,12]$. Presepsin was first detected by biochemical methods and has been considered a new biomarker for infection in Japan [13]. A meta-analysis in 2015 confirmed its diagnostic accuracy $[11,14]$, and the prognostic accuracy of presepsin in sepsis has been reported in several clinical studies $[8,10,15$ 19]. In Korea, presepsin levels were significantly higher in the infected group than in the uninfected group. Moreover, the diagnostic accuracy of presepsin is higher than that of other conventional biomarkers [10].

Sepsis is a common disease in hospitalized patients with high morbidity and mortality rates. Therefore, several factors have been studied to enhance the rapid diagnosis of sepsis and predict prognosis. Procalcitonin [20], lactate [21], and interleukin-6 levels are prognostic laboratory markers of sepsis [22,23]. Presepsin has also been studied as a prognostic factor [19].

In this study, the levels of presepsin $(3,112 \pm 3,841 \mathrm{pg} / \mathrm{mL}$ vs. $1,511 \pm 2,092 \mathrm{pg} / \mathrm{mL}, p=0.004$ ) were found to be higher in the non-survivor group than in the survivor group. However, presepsin demonstrated poor performance in predicting the prognosis of sepsis (presepsin: $\mathrm{AUC}=0.656, p=0.001$ ), as confirmed by the ROC curve analysis in this study. This study showed that the mean age of patients in the non-survivor group was higher than that of the survivor group. Giavarina et al. [24] reported that presepsin concentrations were higher in patients aged $\geq 70$ years compared

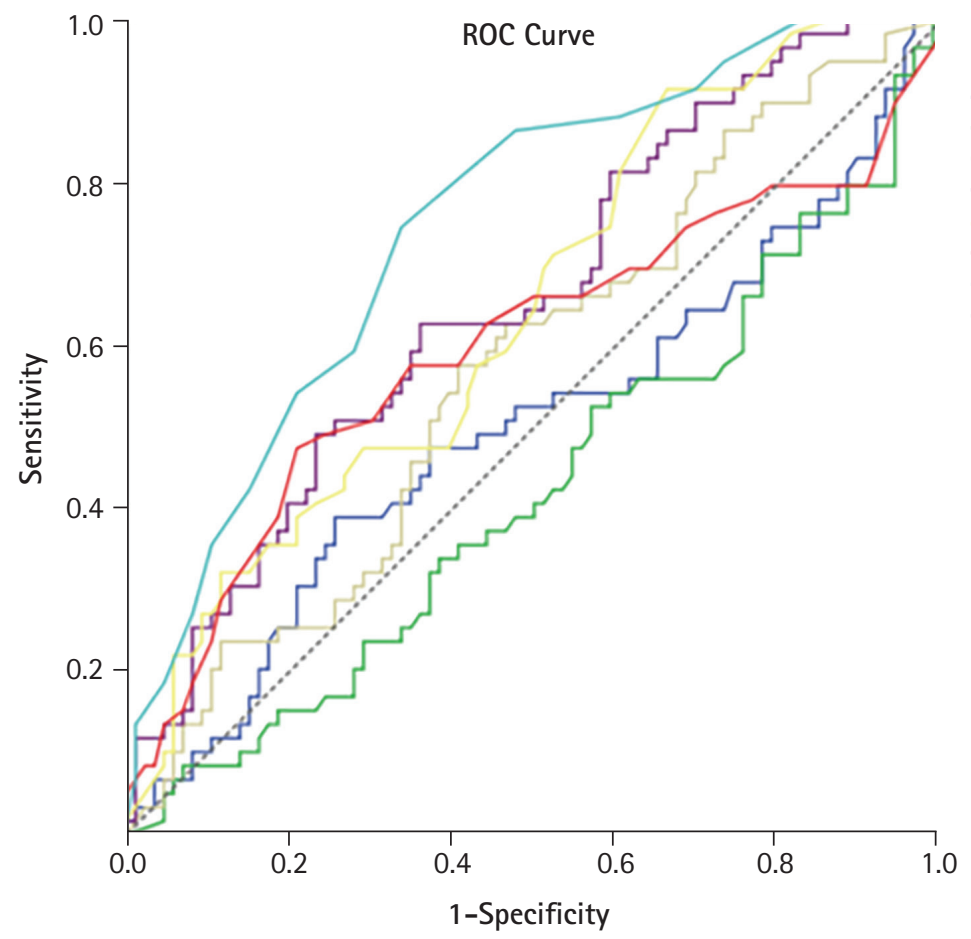

$$
\begin{aligned}
& \text { - WBC } \\
& \text { - CRP } \\
& \text { - Procalcitonin } \\
& \text { - Presepsin } \\
& \text { - Lactate } \\
& \text { - APACHE II } \\
& \text { - SOFA score } \\
& \text { - - Reference line }
\end{aligned}
$$

Fig. 3. Receiver operating characteristic (ROC) curves of the presepsin levels, procalcitonin levels, lactate levels, and the SOFA score in predicting patients' in-hospital mortality. WBC, white blood cells; CRP, C-reactive protein; APACHE II, Acute Physiology and Chronic Health Evaluation II; SOFA, sequential organ failure assessment. 
to younger patients ( $87 \%$ vs. $47 \%, p<0.001)$. This result suggests that presepsin levels might be altered and have relatively poor predictive potential in elderly patients with sepsis in the ICU. However, several studies have shown that presepsin levels are higher in non-survivors among patients with sepsis, and some studies have shown presepsin to be a statistically significant prognostic factor. Moreover, Wen et al. [18] showed that presepsin levels in the non-survivor group were significantly higher $(1,692 \mathrm{pg} / \mathrm{mL}[1,028$ $4,286 \mathrm{pg} / \mathrm{mL}]$ vs. $1,125 \mathrm{pg} / \mathrm{mL}[484-2,268 \mathrm{pg} / \mathrm{mL}], p=0.000)$, $p=0.000)$ and that presepsin levels were an independent risk factor for in-hospital mortality in patients with sepsis (OR, 1.221; $p=0.026$ ). ROC curve analysis showed that presepsin levels are good predictors of in-hospital mortality in patients with sepsis $(\mathrm{AUC}=0.703, p=0.000)$ [18]. Furthermore, Jereb et al. [25] showed that presepsin levels were higher in patients with septic shock than in patients with sepsis $(1,914 \mathrm{pg} / \mathrm{mL}[342-20,000 \mathrm{pg} /$ $\mathrm{mL}]$ vs. $771 \mathrm{pg} / \mathrm{mL}[286-5,565 \mathrm{pg} / \mathrm{mL}], p<0.01)$. Mean presepsin concentrations were higher in the non-survivors $(1,941 \mathrm{pg} / \mathrm{mL}$ [342-20,000 pg/mL] vs. $1,208 \mathrm{pg} / \mathrm{mL}[286-12,096 \mathrm{pg} / \mathrm{mL}]$, $p=0.009)$. The trend of changes in presepsin concentrations in the deceased patients was significantly different from that in the surviving patients $(p=0.018)$ [25]. Masson et al. [26] showed that the presepsin levels were higher in decedents $(2,269 \mathrm{pg} / \mathrm{mL}$ $[1,171-4,300 \mathrm{pg} / \mathrm{mL}])$ than in survivors $(1,184 \mathrm{pg} / \mathrm{mL}[875-$ $2,113 \mathrm{pg} / \mathrm{mL}] ; p=0.002)$. The evolution of presepsin levels over time was significantly different between survivors and decedents ( $p$ for time-survival interaction $=0.03$ ). Furthermore, presepsin levels were associated with ICU stay and 28-day mortality (hazard ratio, 1.55; 95\% CI, 1.12-2.13; $p=0.008$ ) in Cox models adjusted for clinical characteristics [26]. The cutoff values of presepsin levels that predict mortality in patients with sepsis have been identified to lie between 556 and 2,455 ng/L [17,19,27-29]. However, in some studies, presepsin levels did not show any significance in predicting mortality $[10,16,28]$. In other studies, the prognostic value of presepsin was different, and the cutoff value was not clear $[7,17,25,30]$. It is thought that the non-severe patient groups were not comparable; the differences in the underlying disease and the degree of infection influenced the outcome. In this study, the number of patients was small, and patients with underlying hematologic malignancy were included; therefore, it is thought that this may have influenced the study results. Considering these points, it is believed that further studies involving a larger number of patients with a similar underlying disease would be helpful in identifying the prognostic factors.

There are some limitations to our study. First, the sample size was relatively small. The number of patients included in each group was relatively small, and no bacterial, fungal, or viral etiolo- gies were identified. Therefore, a large-scale multicenter study is needed. Second, this was a single-center study that could have led to selection biases. Third, patients' presepsin levels were measured only during hospitalization and were not monitored daily.

In conclusion, the diagnosis of sepsis and prediction of prognosis are important. Although scoring systems such as the SOFA score provide assistance, the scores need to be calculated by the clinicians; hence, the score cannot be checked immediately. Thus, the importance of laboratory markers that can quickly identify sepsis is increasing. Presepsin levels were higher in the deceased group, and mortality was predictable at a cutoff level of $1,716 \mathrm{mg} / \mathrm{mL}$. However, the ROC curve did not show any significant values. Additional studies, such as multicenter studies, would be helpful.

\section{Notes}

\section{Ethical statements}

This study was approved by the Institutional Review Board (IRB) of Chungnam University (IRB No: CNUH 2020-06-074), and the requirement for informed consent was waived because of the retrospective nature of the study.

\section{Conflicts of interest}

No potential conflict of interest relevant to this article was reported.

\section{Author contributions}

Conceptualization, Data curation: JSK, SIL; Formal analysis: JSK, YJK, SIL; Methodology: JSK, JEL, SIL; Visualization: JSK, DHK, SIL; Writing-original draft: JSK, SIL; Writing-review \& editing: all authors.

\section{ORCID}

Jeong Suk Koh, https://orcid.org/0000-0002-4251-7310

Yoon Joo Kim, https://orcid.org/0000-0002-9028-0872

Da Hyun Kang, https://orcid.org/0000-0002-3495-0931

Jeong Eun Lee, https://orcid.org/0000-0001-6173-2748

Song-I Lee, https://orcid.org/0000-0001-8372-4511

\section{References}

1. Singer M, Deutschman CS, Seymour CW, Shankar-Hari M, Annane D, Bauer M, et al. The third international consensus definitions for sepsis and septic shock (Sepsis-3). JAMA 2016; 315:801-10.

2. Kim JH, Hong SK, Kim KC, Lee MG, Lee KM, Jung SS, et al. Influence of full-time intensivist and the nurse-to-patient ratio 
on the implementation of severe sepsis bundles in Korean intensive care units. J Crit Care 2012;27:414.

3. Park DW, Chun BC, Kim JM, Sohn JW, Peck KR, Kim YS, et al. Epidemiological and clinical characteristics of community-acquired severe sepsis and septic shock: a prospective observational study in 12 university hospitals in Korea. J Korean Med Sci 2012;27:1308-14.

4. Annane D, Siami S, Jaber S, Martin C, Elatrous S, Declère AD, et al. Effects of fluid resuscitation with colloids vs crystalloids on mortality in critically ill patients presenting with hypovolemic shock: the CRISTAL randomized trial. JAMA 2013;310:180917.

5. Rivers E, Nguyen B, Havstad S, Ressler J, Muzzin A, Knoblich B, et al. Early goal-directed therapy in the treatment of severe sepsis and septic shock. N Engl J Med 2001;345:1368-77.

6. Gaieski DF, Edwards JM, Kallan MJ, Carr BG. Benchmarking the incidence and mortality of severe sepsis in the United States. Crit Care Med 2013;41:1167-74.

7. Kaukonen KM, Bailey M, Suzuki S, Pilcher D, Bellomo R. Mortality related to severe sepsis and septic shock among critically ill patients in Australia and New Zealand, 2000-2012.JAMA 2014; 311:1308-16.

8. Brodska H, Valenta J, Pelinkova K, Stach Z, Sachl R, Balik M, et al. Diagnostic and prognostic value of presepsin vs. established biomarkers in critically ill patients with sepsis or systemic inflammatory response syndrome. Clin Chem Lab Med 2018;56: 658-68.

9. Mihajlovic D, Brkic S, Uvelin A, Draskovic B, Vrsajkov V. Use of presepsin and procalcitonin for prediction of SeptiFast results in critically ill patients. J Crit Care 2017;40:197-201.

10. Kweon OJ, Choi JH, Park SK, Park AJ. Usefulness of presepsin (sCD14 subtype) measurements as a new marker for the diagnosis and prediction of disease severity of sepsis in the Korean population. J Crit Care 2014;29:965-70.

11. Zhang X, Liu D, Liu YN, Wang R, Xie LX. The accuracy of presepsin (sCD14-ST) for the diagnosis of sepsis in adults: a meta-analysis. Crit Care 2015;19:323.

12. Zou Q, Wen W, Zhang XC. Presepsin as a novel sepsis biomarker. World J Emerg Med 2014;5:16-9.

13. Okamura Y. Usefulness of presepsin measurement: a new biomarker for sepsis. Rinsho Byori 2015;63:62-71.

14. Zhang J, Hu ZD, Song J, Shao J. Diagnostic value of presepsin for sepsis: a systematic review and meta-analysis. Medicine (Baltimore) 2015;94:e2158.

15. Hassan EA, Abdel Rehim AS, Ahmed AO, Abdullahtif H, Attia A. Clinical value of presepsin in comparison to hsCRP as a monitoring and early prognostic marker for sepsis in critically ill patients. Medicina (Kaunas) 2019;55:36.

16. Kondo Y, Umemura Y, Hayashida K, Hara Y, Aihara M, Yamakawa K. Diagnostic value of procalcitonin and presepsin for sepsis in critically ill adult patients: a systematic review and meta-analysis. J Intensive Care 2019;7:22.

17. Ali FT, Ali MA, Elnakeeb MM, Bendary HN. Presepsin is an early monitoring biomarker for predicting clinical outcome in patients with sepsis. Clin Chim Acta 2016;460:93-101.

18. Wen MY, Huang LQ, Yang F, Ye JK, Cai GX, Li XS, et al. Presepsin level in predicting patients' in-hospital mortality from sepsis under sepsis-3 criteria. Ther Clin Risk Manag 2019; 15:733-9.

19. Yang HS, Hur M, Yi A, Kim H, Lee S, Kim SN. Prognostic value of presepsin in adult patients with sepsis: systematic review and meta-analysis. PLoS One 2018;13:e0191486.

20. Yunus I, Fasih A, Wang Y. The use of procalcitonin in the determination of severity of sepsis, patient outcomes and infection characteristics. PLoS One 2018; 13:e0206527.

21. Yu G, Yoo SJ, Lee SH, Kim JS, Jung S, Kim YJ, et al. Utility of the early lactate area score as a prognostic marker for septic shock patients in the emergency department. Acute Crit Care 2019; 34:126-32.

22. Larsen FF, Petersen JA. Novel biomarkers for sepsis: a narrative review. Eur J Intern Med 2017;45:46-50.

23. Zhang Y, Khalid S, Jiang L. Diagnostic and predictive performance of biomarkers in patients with sepsis in an intensive care unit. J Int Med Res 2019;47:44-58.

24. Giavarina D, Carta M. Determination of reference interval for presepsin, an early marker for sepsis. Biochem Med (Zagreb) 2015;25:64-8.

25. Jereb M, Mavric M, Skvarc M, Drobnic A, Dolenc S, Strunjas NP, et al. Usefulness of presepsin as diagnostic and prognostic marker of sepsis in daily clinical practice. J Infect Dev Ctries 2019;13:1038-44.

26. Masson S, Caironi P, Spanuth E, Thomae R, Panigada M, Sangiorgi G, et al. Presepsin (soluble CD14 subtype) and procalcitonin levels for mortality prediction in sepsis: data from the Albumin Italian Outcome Sepsis trial. Crit Care 2014;18:R6.

27. Liu B, Chen YX, Yin Q, Zhao YZ, Li CS. Diagnostic value and prognostic evaluation of Presepsin for sepsis in an emergency department. Crit Care 2013;17:R244.

28. Kim H, Hur M, Moon HW, Yun YM, Di Somma S; GREAT Network. Multi-marker approach using procalcitonin, presepsin, galectin-3, and soluble suppression of tumorigenicity 2 for the prediction of mortality in sepsis. Ann Intensive Care 2017; $7: 27$.

29. Carpio R, Zapata J, Spanuth E, Hess G. Utility of presepsin (sCD14-ST) as a diagnostic and prognostic marker of sepsis in 
the emergency department. Clin Chim Acta 2015;450:169-75.

30. Zhu Y, Li X, Guo P, Chen Y, Li J, Tao T. The accuracy assessment of presepsin (sCD14-ST) for mortality prediction in adult patients with sepsis and a head-to-head comparison to PCT: a meta-analysis. Ther Clin Risk Manag 2019;15:741-53. 